\title{
Price Indices for Information and Communication Technology Industries - An Application to the German PC Market
}

\author{
by \\ Dietmar Moch \\ Zentrum für Europäische Wirtschaftsforschung (ZEW), Mannheim
}

March 2001

\begin{abstract}
Changing product quality, rapid technological progress, and short product life cycles make it difficult to compute indices that correctly reflect the true price movements of IT products. This paper assesses the differences between traditional and quality adjusted indices by providing results for PC hardware. Transaction price data for the period from 1985 to 1994 are used to construct price indices for personal computers in Germany.
\end{abstract}

The use of hedonic methods allows to correct for quality changes. Quality-adjusted hardware prices decline by 34 percent on average per year according to our hedonic index. The estimation confirms the importance of quality adjustment since the decline of average prices at 7 percent p.a. is substantially lower, thus overestimating computer prices and inflation.

When the hedonic index for German computer prices is compared to various indices calculated for the US market it seems that the decline of quality adjusted prices in Germany has been significantly higher than in the US. However if prices are converted to US\$ the average decline is about 30 percent which is consistent with results for the US.

\footnotetext{
${ }^{*}$ I gratefully acknowledge the financial support in funding this resarch from the German Science Foundation (Deutsche Forschungsgemeinschaft, DFG) under grant LI681/2-1 and from the Federal Statistical Office Germany (Statistisches Bundesamt) under the project „Einsatzmöglichkeiten hedonischer Techniken in der amtlichen Statistik“.
} 


\section{Non-Technical Summary}

Die Berechnung von Preisindizes zeigt für Deutschland ein ähnliches Bild wie in den USA. Die starken Qualitätsverbesserungen schlagen sich nicht in erhöhten Preisen nieder. Dadurch weisen Preisindizes, die keine Qualitätsverbesserungen berücksichtigen - wie in der amtlichen Statistik üblich - zu hohe Indexzahlen aus. Der Preisrückgang wird unterschätzt, d.h. die Inflation wird zu hoch ausgewiesen. Bei der Analyse der Preisentwicklung für PCs in Deutschland (bezogen auf den Direktmarkt) gingen die nominalen Preise 1985 bis 1994 um ca. 7\% jährlich zurück, während der hedonische, qualitätskorrigierte Preisindex einen Rückgang von 34\% jährlich auswies. Kontrolliert man für den Wechselkurs zum Dollar (der Dollar ging in dem Zeitraum von über 3 DM bis auf unter 1,50 DM zurück, und die Preise für die Komponenten wie Festplatten, Speicher, Prozessoren, usw., die aus Fernost oder USA importiert werden, werden in Dollar abgerechnet), so bleiben noch ein Rückgang von 1\% p.a. des nominalen und ein Rückgang von 30\% des hedonischen Indexes. Diese Werte werden durch vergleichbare Forschungsergebnisse aus den USA bestätigt .

Der deutliche Unterschied zwischen nominaler und hedonischer Preisentwicklung bei Computern und bei Software läßt vermuten, daß auch bei anderen Gütern, die einen raschen technologischen Fortschritt aufweisen, der Index der amtlichen Statistik die Inflation zu hoch ausweist. 


\section{Introduction}

"In the presence of quality changes, the standard methods of computing price indexes may lead to biased results." Griliches (1971).

The discussion about the computation of price indices which control for quality changes has started early in the U.S. and has received considerable attention lately. The report by the United States Advisory Commission to study the Consumer Price Index Boskin et al. (1996) led to an intensive discussion about distortions arising from unobserved quality changes. The results showed that traditional methods of index construction based on matching model approaches overestimate inflation by about 1 percentage point each year. Though there is evidence from household appliances $^{l}$, cars, and software ${ }^{2}$ suggesting that these results also hold for Germany, there is neither a broad discussion about quality correction methods nor any usage of hedonic techniques in the official German indices.

Despite the fact that price indices are the “... informational foundation upon which virtually everything we know about economy rests." ${ }^{3}$ and despite price index numbers widely being used in making economic policy, there is little attention being paid to the construction of price index series in Germany. The discussion about the productivity paradox suggests that there is a close link between problems to identify productivity growth and the measurement of quality of products and services. Underestimation of output due to poor measurement, with technological progress and quality improvements not adequately accounted for, is supposed to be an important issue to explain the paradox. Strikingly, the technologies that are supposed to spur productivity growth most, i.e. information and communications technologies and services, suffer from this measurement problem.

Especially in the service sector, investments in IT and particularly investments in personal computers and software are very important. However, while IT was about 2.13 percent of Germany's gross domestic product ${ }^{4}$ - there is no official price deflator for IT products and services. Since the economic importance of IT products is bound to increase further, the measurement of prices for this type of goods has become an important topic for economic research.

The quality of information technology has improved dramatically over the last decades, driven by

\footnotetext{
${ }^{1}$ Hoffmann (1998)

${ }^{2}$ Harhoff and Moch (1997)

${ }^{3}$ Boskin (1997)

${ }^{4}$ EITO (1999) p. 49
} 
the technological progress in the semiconductor industry. According to Gordon Moore the capacity of semiconductor devices doubles every 18 months. While technology has been developing rapidly in the PC market, nominal prices have either decreased or just maintained their level. Hardware components in the computer industry therefore have been among the favorite examples for the application of hedonic price indices. There is a number of recent studies on the decline of qualityadjusted prices for personal computers that are of particular relevance for this article. Gordon (1990), Berndt and Griliches (1993), Nelson et al. (1994), and Berndt et al. (1995) have shown that quality-adjusted prices for PCs decline on average by 25-30 percent per annum in the US.

The evidence on Germany is less well-developed. A study by Gnoss (1994) yields a yearly average decline of about 12 percent for list prices of micro-computers ${ }^{5}$. The official price index for the private cost of living also includes personal computers ${ }^{6}$ and shows an average annual change of 7.19 percent which is even lower than the results published by Gnoss. Both indices are significantly lower than the data published by US statistical agencies.

This study provides some new evidence on the quality-adjusted development of prices for PCs in the years 1985 to 1994 . Using a relatively large sample of observations on prices and product characteristics, we compute several price indices for PC hardware in the Federal Republic of Germany and compare them to the German official price index and to results observed in the US market. In order to focus on a reasonably homogeneous market, we analyze the price development of MS-DOS compatible Personal Computers. This does not seem to be a strong restriction since Apple has never achieved a substantial market share in Germany as it did in the US.

The paper proceeds as follows: Section 2 briefly describes the construction of price indices and the basic elements of hedonic theory. In Section 3 the data set and the variables used to model the quality of PC products are described. Section 4 presents regression results for a hedonic index and comments on the differences between hedonic, average, and matched model price series. Section 5 summarizes the empirical results from this study and compares them to the results that were observed in the US market.

\section{Hedonic Price Indices}

Statistical agencies often use the matched-model method to compute price series. The resulting indices are also referred to as chained price indices. This procedure is described in detail by Triplett (1990) for the United States and in Szenzenstein (1995) and Hoffmann (1998) for

\footnotetext{
${ }^{5}$ microcomputers include personal computers, workgroup servers and micro servers alike.
} 
Germany. In essence, the price index is computed as the ratio of successive prices for the same good (or bundle of goods). Obviously, in employing the matched model approach a decision has to be made whether a given product is similar enough to some product from the previous period so that a link can be established. The price index is then computed as a weighted average over all price changes computed from linked products. This classical method is appropriate for products that maintain their quality characteristics over time either fully or to a large extent. Thus, computing price indices for commodities like crude oil, cement, or grain, to give just a few examples, is indeed a relatively simple task. In many cases, however, the chaining of products may either be infeasible (e.g., if a completely new product appears) or highly unreliable, e.g., if the products whose prices are chained intertemporarily are subject to considerable quality changes. Furthermore it is more difficult to obtain price indices for goods that can be thought of as bundles of characteristics which are subject to change. ${ }^{7}$ The computation of hedonic price indices which control for various quality changes is regarded to be a potential safeguard against such distortions.

\subsection{Theoretical Background}

Since the problem of obtaining price indices in the presence of quality changes has received considerable attention lately, we only provide a brief summary of the theoretical background. Detailed discussions have been given, inter alia, by Griliches (1971), Muellbauer (1974) and Rosen (1974). A critical discussion of the hedonic method and the description of alternatives is provided by Trajtenberg (1990).

The hedonic analysis starts from the assumption that the utility consumers can derive from a good is determined by a set of characteristics that implicitly describe the good. The hedonic technique uses these characteristics to decompose the price of a good into a quality and a time component. Only the latter component is taken into account when the price index is computed. If we can observe the price $\mathrm{p}$ of the products and a vector of variables $\mathrm{X}$, describing the product's quality characteristics, the structural part of a hedonic price equation can be written as $g(p)=f(X, \beta)$, where $\beta$ is a vector of parameters to be estimated.

\subsection{Choice of the Functional Form}

The theoretical considerations on utility and cost functions and their identification still leave room to the specification of the functional form used. The functions $g($.$) and f($.$) are often assumed to be$

\footnotetext{
${ }^{6}$ Statistical Office Germany, Wiesbaden Segment 3303, Reihe 505, Nr. 003270141

${ }^{7}$ See Hoffmann (1998) for a detailled discussion of the methods used and the effort taken by the German statistical agency.
} 
linear in their respective arguments. A linear utility function includes the assumption on the separability of utility providing characteristics. The linear model even assumes that the quality characteristics are perfect substitutes. However this is only partially true for the quality characteristics of a PC. A second floppy disk drive can be a substitute for a hard disk drive, since it allows to have the operating system and the application software on one disk and the data on another. Additional hard disk space or a second floppy drive can for instance not totally substitute main memory, because a PC needs a minimum amount of main memory to run at all.

Therefore, we will not consider a linear model and like most other studies on computer hardware, we will use a double-logarithmic specification of the type $\log p=\log X \beta$ for the structural part of the equation so that the parameter vector $\beta$ can be interpreted as a vector of elasticities. Besides, the model using the double-logarithmic specification is constructed like a Cobb-Douglas production function. Using this specification for the utility function gives us some advantages in describing the utility that can be derived from a personal computer.

First there is restricted substitutability between characteristics, i.e. a characteristic can not be totally substituted. If at least one of the input factors takes the value zero, e.g. a PC without any main memory, the utility function takes the value zero. Second $\lim _{x_{i} \rightarrow \infty} \frac{\partial u}{\partial x_{i}}=\lim _{x_{i} \rightarrow \infty} \frac{\beta_{i}}{x_{i}}=0$ ensures that the level of utility one can derive from a characteristic is bounded and decreasing in units of this particular characteristic. Third the use of a CD-type utility function allows complementary effects between attributes.

The computation of the price index from the double-logarithmic specification can best be explained using a simple example. Assume that there are price and quality observations for a large number of products for three years (say 1990, 1991, and 1992). For simplicity let us assume further that only one quality characteristic $\mathrm{x}$ is of relevance. The relevant price-quality regression equation for product $i$ in year $t$ is then given by

$\ln p_{i t}=\alpha+\beta \ln x_{i t}+\delta_{91} D_{91}+\delta_{92} D_{92}+\varepsilon_{i t}$

where the disturbance terms are assumed to be independently distributed ${ }^{8}$ and the year 1990 is taken to be the reference year for the time dummy variables $\mathrm{D}_{91}$ and $\mathrm{D}_{92}$. In this case, the price index can be computed in a particularly simple way. Holding product quality characteristics $x_{i t}$ constant, the parameter estimate $\hat{\delta}_{91}$ is identical to the estimated price difference $\ln \hat{p}_{91}-\ln \hat{p}_{90}$. 
The estimated price ratio and thus the price index is then given by $\exp \left(\hat{\delta}_{91}\right)$. The exponentiated coefficient of the time dummy variables is therefore an estimate of the respective price index relative to the reference year. This is the approach taken in the following sections.

\subsection{A Hedonic Price Index Function for Personal Computers}

Personal computers are a particularly suitable example for the construction of quality-adjusted price indices, since it is intuitively clear that a direct comparison of a typical PC bought at the beginning of the Eighties bears little resemblance to a typical personal computer of more recent vintage. Table 1 shows that in objective terms, such as computational speed and storage capacity, the quality of these products has increased considerably. Most of the models have one or more of these characteristics changed from one month to another, even if they keep their model name, e.g. when producers add a larger hard disk or additional memory to the package. In our data set on average only about 44 percent of the observations of one particular month can be linked directly to an observation in the previous month if the link includes the full technical specification ${ }^{9}$, the brand and model name and the outlet where the product is sold. Reducing the tightness of matching to the level of full technical specification still leaves us with only 54 percent of the observations. Matching to the type of processor makes use of 99 percent of the observations. This type of matching, however, would ignore the advances in all components of a PC except the processor. Suppose for a moment that the nominal prices of computers had remained at the same level. A naive chained price index which does not take quality changes into account would show no signs of either increase or decline. Yet, given that quality has improved, it is clear that the true price index should be declining.

However using the logarithmic transformation of the variables entails some problems. If the quantity variable can take the value zero the logarithm is not defined. In our data set there are three attributes, the size of the hard disk, the size of the second level cache and the number of applications bundled with the package that may take the value zero in some observations. One of the basic assumptions of the hedonic model implies that the consumer has the possibility to do arbitrage between different combinations of attributes, e.g. we assume that the user can upgrade from a $100 \mathrm{MB}$ hard disk to a $200 \mathrm{MB}$ hard disk and has to pay only the equivalent of the difference in utility levels and the upgrade is virtually free, i.e. there are no switching costs. For all models

\footnotetext{
${ }^{8}$ In our empirical study, we use the heteroskedasticity-robust variance-covariance proposed by White (1980) to account for non-identically distributed error terms.

${ }^{9}$ Full technical specification includes: Processor type and speed, size of main memory, size of second level cache, bus type, size of first and second floppy drive size of harddisk, cd-rom drive, type of graphics adapter, size of video memory, type of display and size of display.
} 
which are offered without hard disk we assume that they have a built-in hard disk of $10 \mathrm{MB}^{10}$ capacity. To control for the effects of this assumption we include the dummy variable NOHD which takes the value one if the original model did not include a hard disk and zero otherwise. Accordingly we assume that systems include $32 \mathrm{kByte}$ second level cache and at least one software application and introduce the dummy variables NOCACHE and NOAPPS which take the value one if the basic variable takes the value zero and zero otherwise.

This leads us to the following specification of the hedonic model ${ }^{11}$ :

$$
\begin{aligned}
\ln p_{i t}= & \alpha+\beta_{1} L N I C O M P+\beta_{2} P R O C 32+\beta_{3} L N C A C H E+\beta_{4} N O C A C H E \\
& +\beta_{5} D_{-} B U S 16+\beta_{6} D_{-} B U S 32 \\
& +\beta_{7} L N M E M+\beta_{8} L N H D M B+\beta_{9} N O H D+\beta_{10} D_{-} F D 2+\beta_{11} C D R O M \\
& +\beta_{12} L N D S I Z E+\beta_{13} D_{-} D C O L O R+\beta_{14} L N V M E M \\
& +\beta_{15} M O U S E+\beta_{16} L N A P P S+\beta_{17} N O A P P S+\beta_{18} O S+\beta_{19} \text { TOWER } \\
& +\delta_{2} Q_{2}+\ldots+\delta_{40} Q_{40}+\varepsilon_{i t}
\end{aligned}
$$

(LNICOMP $=\ln ($ ICOMP performance rating); PROC32 $=$ dummy for 32-Bit processor; LNCACHE $=\ln ($ size of second level cache); D_BUS16 = dummy for ISA 16-Bit systembus; D_BUS32 = dummy for PCI, VLB or EISA 32Bit systembus; LNMEM $=\ln ($ main memory); LNHDMB $=\ln ($ hard disk capacity); NOHD = dummy for no hard disk included; D_FD_2 = dummy for 2 floppy drives included; CDROM = dummy for cd-rom drive included; LNDSIZE = $\ln$ (display size); D_DCOLOR = dummy for color display; LNVMEM = $\ln$ (video memory); MOUSE = dummy for mouse included; LNAPPS $=\ln ($ number applications in bundle); NOAPPS $=$ dummy for no applications included; OS = dummy for operating system included; TOWER = dummy for tower case; $Q=$ dummy for time period $^{12}$

\section{Data and Variable Definitions}

\subsection{Data Sources and Collection}

The empirical use of hedonic techniques to construct price indices requires detailed information on prices and quality-related product characteristics. To study the relationship between quality and product price we use a large data set on PCs that were offered in the period from 1985 to 1994 in the mail order market in the Federal Republic of Germany ${ }^{13}$.

There are a number of reasons to sample prices from mail order advertisements. First, a price index should record real transaction prices as closely as possible. Arguably, mail order prices are better measures of actual transactions' prices than - say - list prices which are often subject to

\footnotetext{
${ }^{10}$ Though the data include 6 observations with a 5MB Harddisk. Models with 10MB capacity (284 obs.) have been the most preferred alternative to the bundles that did not include a harddisk.

${ }^{11}$ We will refer to it as model (1).

${ }^{12}$ More detailed explanations of the variables are given in section 3.2

${ }^{13}$ We are indebted to Ulrich Van Douwe who provided us with this dataset. For a detailed description of this dataset please see also Douwe (1996).
} 
considerable rebates. The mail order market was also chosen because there are no big differences in the service provided by the vendor that could be included in the price. Moreover, there is no market power that can be derived from the lack of local competition, since all companies offer their products throughout Germany. Another reason is the constantly rising share of this particular distribution channel for PC hardware. In addition, buyers and producers alike use the price information from the mail order market for comparisons even if they do not participate in this market. The price data were collected retrospectively from advertisements in CHIP which until 1992 used to be the leading magazine for personal computing in Germany. This magazine contains advertisements of retailers that offer their products to private buyers and to businesses alike.

In 1976 Steve Jobs and Steven Wozniak developed the first computer for individuals - though the name PC didn't exist it was the first personal computer - that brought computing power to the desktop. IBM entered the market with its first PC in 1981. In the following years the IBM based PC with an INTEL microprocessor and a Microsoft operating system became the dominant design. The other designs have never gained substantial market share with professional users. Therefore we selected only products following the dominant IBM design. There were a few advertisements for PC hardware in 1984, but because their number was so small the data set starts in the year 1985. Only complete systems consisting of a central processing unit (CPU), at least one floppy disk drive, keyboard, and a monitor were considered. Neither used systems offered by private persons nor packages including a printer were selected. Since summer 1991 advertisements with a tabular description of possible components and their prices have been gaining importance. Because there is a huge number of possible combinations three combinations were chosen from each advertisement: one with the cheapest components possible, one with the most expensive, and a medium package. Hedonic regressions require detailed information on product quality, therefore only advertisements providing sufficient quality information could be included. Despite these restrictions the hardware data include 10834 observations $^{14}$ from the years 1985 to 1994, with prices taken on an monthly basis from issues of CHIP magazines of the respective year.

\subsection{Relevant Quality Characteristics and Definitions of Variables}

The basic architecture of a IBM-compatible Personal Computer has remained unchanged since its introduction in 1981. The dominant component is the INTEL microprocessor which makes use of random access and permanent memory to process and store data that are displayed by a graphics

\footnotetext{
${ }^{14}$ The original dataset contains 29635 observations. 18741 observations were products offered by Rheintec, that have been dropped. Rheintec had far less than one per cent market share and was moving from low-cost to more expensive offerings. Therefore Rheintec was excluded to avoid possible bias of regression results. Furthermore 617 observations that were wrongly classified $80386 \mathrm{SX}$ systems have been renamed to be DX systems.
} 
adapter on a display. Generally speaking, the PC is a set of components which use standardized interfaces to cooperate, and the producers are rather assembling the PC from marketed components than building a complete system on their own. Finally the consumers can use this componentarchitecture to upgrade a system and thus do arbitrage. These components can be described by a set of objectively measurable criteria which are determined by their physical structure. The quality of a $\mathrm{PC}$ will therefore be described by a framework of four quality dimensions.

Speed. The performance of a system depends not only on the components but also on the combination they are used in. Since no benchmark tests were available for the single systems, we had to confine ourselves to the dominating components: The INTEL microprocessor and the system bus architecture ( 8 -Bit vs. 16-Bit or 32 Bit design). For their new products INTEL published benchmark results - the so called ICOMP index - indicating the computing power of each processor. For the older processor generations, MIPS rates were used to approximately calculate the ICOMP values in order to have a consistent performance measure for all observations. The introduction of the Intel 80386 processor was a major improvement in the PC architecture. The memory management which had been virtually unchanged since the introduction of the original PC had become a serious barrier to innovations in the complementary software. The graphical user interfaces ${ }^{15}$ required more main memory than the old 16 -Bit architecture ${ }^{16}$ could deliver. The 32-Bit memory model is able to address 4GB of memory, enough to build powerful and comfortable applications. Therefore we included the dummy variable PROC32 which takes the value one if the processor architecture uses 32 Bit. $^{17}$

Capacity. There are four quality variables representing the capacity, which is the amount of data a system can process and store. First there is temporary storage represented by the variable LNMEM which is the logarithm of the size of the main memory in megabytes. Second there is permanent storage represented by LNHDMB which is the logarithm of hard disk capacity measured in megabytes. In the early days of the PC hard disk drives were quite expensive. Therefore a number of packages included a second floppy disk drive to allow the user to work without permanently having to switch disks. The dummy variable D_FD2 takes the value one if a second floppy drive exists and zero otherwise. We did not include a variable for the first floppy drive in the package since the specification requires at least one floppy drive and all observations include at least one. The dummy variable CDROM takes the value one if a CD-ROM drive is built in the system and

\footnotetext{
${ }^{15}$ Microsoft's MS Windows, Digital Research's GEM

${ }^{16}$ MS-DOS and its application software were basically 8-Bit software using only some of the benefits that 16-Bit programming could deliver.

${ }^{17}$ This includes also $80386 \mathrm{SX}$ which is based on the 80386DX kernel uses a 16-Bit interface to the motherboard like the 80286 family.
} 
zero otherwise. In the last years CD-ROM drives became very popular because the installation of software packages required more and more floppy disks.

Since DRAM access cycles are quite slow compared to processor frequency a small amount of far more expensive static RAM is used to cache the most recently used parts of the memory. This allows higher performance because the processor normally does not have to wait for slow DRAM. The variable LNCACHE is the logarithm of the KBytes of cache memory installed. The system bus width also has a great influence on the I/O performance of a computer system. The dummy variable D_BUS16 takes the value one if the board has a 16 bit ISA bus and zero otherwise. The dummy variable D_BUS32 takes the value one if the system contains a 32 bit bus system that meets the specifications of EISA, VLB, PCI or MCA and zero otherwise.

Video. The display has received considerable improvements in color depth and resolution and has thus enabled the introduction of graphical user interfaces. The video quality is determined by the display and the graphics adapter that are described by the following dimensions: The variable LNDSIZE is the logarithm of the display size measured in inches. The variable LNVMEM is the logarithm of the memory installed on the graphics adapter measured in KBytes. It represents the possible color and pixel resolutions. Especially in the years before 1990, there were considerable differences in the prices of color and monochrome displays. The dummy variable DCOLOR takes the value one if the display is a color display.

Accessories. There is some peripheral equipment that is packed with some of the computer systems. All packages include a keyboard ${ }^{18}$. The MOUSE dummy takes the value one if there is a computer mouse included and zero otherwise. Any computer needs an operating system and application software in order to be used. The OS dummy is set to unity if a version of the MS-DOS operating system is included. The variable LNAPPS is the logarithm of the number of applications that are in the package. The cabinets of powerful models are often in a Tower design with a stronger power supply and more expansion slots. Therefore we included the dummy variable TOWER which takes the value one if the computer is in a tower and zero if it is a mini or a desktop cabinet.

Time Variables. To describe the time trend of prices, we use quarterly dummies Q2,..,Q40 that take the value one if the observation is in the corresponding quarter and zero otherwise. The reference period is Q1 which corresponds to the first quarter in the year 1985.

Dependent Variable. As our dependent variable we use the natural logarithm of the recorded 
product price as it is announced in the advertisement (LNPRICE). Customers have to pay an additional shipping charge of about DM 30-40 which we did not include in our price measure. The price does include a value-added tax of 14 percent from 1986 to 1993, and of 15 percent since then. We adjusted observations from 1986 to 1993 to be comparable with the higher VAT level of the later period. Since prices enter our specification in logarithmic form, the presence of a timeinvariant multiplier due to the VAT does not affect our results. Moreover the indices are also computed with the US Dollar equivalent of the price in Deutsche Mark ${ }^{19}$ to control for financial distortions and thus allow international comparisons.

\subsection{Development of Quality Characteristics}

The following table 1 shows the development of the means of important quality variables. Each year the average model offered was more powerful than the year before. While prices were decreasing, the growth in important quality dimensions was very high, especially if compared to other goods, e.g. cars. Computing power showed about 69 percent AAGR (measured by ICOMP) followed by hard disk capacity (63 percent AAGR) and video memory (62 percent AAGR). Interestingly, main memory grew 'only' at 38 percent annually, though it should have a similar cost function as processors (computing power) and video memory. One possible explanation could be the use of MS-DOS as operating system, which had severe problems using more than 640 KByte of main memory due to its internal architecture. The technical limitations in the complementary software also restricted the demand for main memory. The introduction of the graphical user interface MS-Windows presents another example of how strong the influence of the complementary software on the utility and thus on the demand for PCs actually is. Graphical User interfaces require more video memory since they have a higher resolution ${ }^{20}$ and more colors than text based systems. The demand for video memory more than tripled from 1989 to 1990.

\footnotetext{
${ }^{18}$ Since their introduction only minor changes have been made to the keyboard or the mouse.

${ }^{19}$ Since we assumed that the offers were calculated on the basis of the dollar exchange rate at the time when the ads were given to print, we chose the values of the $10^{\text {th }}$ two months before the ads were published.

${ }^{20}$ The standard VGA specification of $640 \times 480$ pixels with 16 colors requires at least 128 KByte compared to 64 KByte for EGA and 16 KByte for CGA.
} 
Table 1: Mean values of quality variables by year (standard deviations in parentheses)

\begin{tabular}{|c|c|c|c|c|c|c|c|c|c|c|}
\hline & Obs. & $\begin{array}{l}\text { Memory } \\
{[\mathrm{kB}]}\end{array}$ & $\mathrm{MHz}$ & $\begin{array}{l}\text { Icomp } \\
\text { Index }\end{array}$ & $\begin{array}{l}\text { Harddisk } \\
{[\mathrm{MB}]}\end{array}$ & $\begin{array}{l}\text { Display } \\
\text { size } \\
\text { [inch] }\end{array}$ & $\begin{array}{l}\text { Video } \\
\text { memory } \\
{[\mathrm{kB}]}\end{array}$ & $\begin{array}{l}\text { Second } \\
\text { Floppy }\end{array}$ & $\begin{array}{l}\text { price } \\
\text { DM }\end{array}$ & $\begin{array}{l}\text { price } \\
\text { USD }\end{array}$ \\
\hline 1985 & 422 & $\begin{array}{l}324.25 \\
(155.65)\end{array}$ & $\begin{array}{l}4.04 \\
(.36)\end{array}$ & $\begin{array}{l}3.03 \\
(.26)\end{array}$ & $\begin{array}{l}4.76 \\
(6.77)\end{array}$ & $\begin{array}{l}10.44 \\
(1.17)\end{array}$ & $\begin{array}{l}13.21 \\
(8.97)\end{array}$ & .51 & $\begin{array}{l}7243.96 \\
(2655.93)\end{array}$ & $\begin{array}{l}2520.69 \\
(876.08)\end{array}$ \\
\hline 1986 & 787 & $\begin{array}{l}447.76 \\
(216.89)\end{array}$ & $\begin{array}{l}5.92 \\
(2.15)\end{array}$ & $\begin{array}{l}6.10 \\
(4.14)\end{array}$ & $\begin{array}{l}10.64 \\
(11.82)\end{array}$ & $\begin{array}{l}12.44 \\
(.96)\end{array}$ & $\begin{array}{l}19.05 \\
(11.87)\end{array}$ & .38 & $\begin{array}{l}5695.01 \\
(2274.34)\end{array}$ & $\begin{array}{l}2555.30 \\
(1015.25)\end{array}$ \\
\hline 1987 & 1118 & $\begin{array}{l}528.14 \\
(240.01)\end{array}$ & $\begin{array}{l}7.32 \\
(2.98)\end{array}$ & $\begin{array}{l}8.93 \\
(6.80)\end{array}$ & $\begin{array}{l}17.07 \\
(19.31)\end{array}$ & $\begin{array}{l}13.19 \\
(1.02)\end{array}$ & $\begin{array}{l}34.50 \\
(23.37)\end{array}$ & .25 & $\begin{array}{l}4566.93 \\
(2938.53)\end{array}$ & $\begin{array}{l}2464.38 \\
(1576.60)\end{array}$ \\
\hline 1988 & 1237 & $\begin{array}{l}751.86 \\
(509.62)\end{array}$ & $\begin{array}{l}11.56 \\
(4.02)\end{array}$ & $\begin{array}{l}18.13 \\
(11.93)\end{array}$ & $\begin{array}{l}21.22 \\
(21.80)\end{array}$ & $\begin{array}{l}13.57 \\
(.86)\end{array}$ & $\begin{array}{l}57.33 \\
(28.60)\end{array}$ & .13 & $\begin{array}{l}4094.87 \\
(2434.72)\end{array}$ & $\begin{array}{l}2347.76 \\
(1418.94)\end{array}$ \\
\hline 1989 & 1332 & $\begin{array}{l}967.59 \\
(671.25)\end{array}$ & $\begin{array}{l}14.33 \\
(4.97)\end{array}$ & $\begin{array}{l}23.24 \\
(13.92)\end{array}$ & $\begin{array}{l}28.00 \\
(24.52)\end{array}$ & $\begin{array}{l}14.05 \\
(.77)\end{array}$ & $\begin{array}{l}71.57 \\
(81.11)\end{array}$ & .05 & $\begin{array}{l}4085.74 \\
(2322.18)\end{array}$ & $\begin{array}{l}2177.48 \\
(1232.12)\end{array}$ \\
\hline 1990 & 1306 & $\begin{array}{l}1307.05 \\
(811.09)\end{array}$ & $\begin{array}{l}18.98 \\
(7.96)\end{array}$ & $\begin{array}{l}35.88 \\
(21.91)\end{array}$ & $\begin{array}{l}47.62 \\
(35.44)\end{array}$ & $\begin{array}{l}14.40 \\
(1.39)\end{array}$ & $\begin{array}{l}234.71 \\
(205.53)\end{array}$ & .10 & $\begin{array}{l}4491.96 \\
(2157.41)\end{array}$ & $\begin{array}{l}2651.74 \\
(1275.31)\end{array}$ \\
\hline 1991 & 1380 & $\begin{array}{l}1865.09 \\
(1900.62)\end{array}$ & $\begin{array}{l}24.93 \\
(8.00)\end{array}$ & $\begin{array}{l}69.34 \\
(46.77)\end{array}$ & $\begin{array}{l}93.07 \\
(112.48)\end{array}$ & $\begin{array}{l}14.02 \\
(.28)\end{array}$ & $\begin{array}{l}501.19 \\
(432.43)\end{array}$ & .45 & $\begin{array}{l}3683.10 \\
(2306.64)\end{array}$ & $\begin{array}{l}2182.91 \\
(1337.85)\end{array}$ \\
\hline 1992 & 594 & $\begin{array}{l}4037.39 \\
(1728.71)\end{array}$ & $\begin{array}{l}30.58 \\
(9.06)\end{array}$ & $\begin{array}{l}107.20 \\
(64.42)\end{array}$ & $\begin{array}{l}142.69 \\
(104.78)\end{array}$ & $\begin{array}{l}14.30 \\
(.89)\end{array}$ & $\begin{array}{l}725.55 \\
(278.49)\end{array}$ & .63 & $\begin{array}{l}4194.89 \\
(2295.92)\end{array}$ & $\begin{array}{l}2656.34 \\
(1453.15)\end{array}$ \\
\hline 1993 & 1027 & $\begin{array}{l}4472.90 \\
(1300.50)\end{array}$ & $\begin{array}{l}40.93 \\
(12.48)\end{array}$ & $\begin{array}{l}175.29 \\
(82.41)\end{array}$ & $\begin{array}{l}257.56 \\
(131.98)\end{array}$ & $\begin{array}{l}14.07 \\
(.29)\end{array}$ & $\begin{array}{l}779.22 \\
(255.88)\end{array}$ & .47 & $\begin{array}{l}3064.70 \\
(923.81)\end{array}$ & $\begin{array}{l}1891.29 \\
(568.34)\end{array}$ \\
\hline 1994 & 1691 & $\begin{array}{l}6203.35 \\
(2255.38)\end{array}$ & $\begin{array}{l}58.51 \\
(20.74)\end{array}$ & $\begin{array}{l}335.00 \\
(177.76)\end{array}$ & $\begin{array}{l}380.67 \\
(187.38)\end{array}$ & $\begin{array}{l}15.30 \\
(1.73)\end{array}$ & $\begin{array}{l}1038.23 \\
(252.10)\end{array}$ & $\begin{array}{l}.09 \\
(.28)\end{array}$ & $\begin{array}{l}3693.09 \\
(1445.01)\end{array}$ & $\begin{array}{l}2307.30 \\
(905.19)\end{array}$ \\
\hline AAGR & $\begin{array}{l}\text { [per } \\
\text { cent] }\end{array}$ & 38.80 & 34.58 & 68.68 & 62.72 & 4.34 & 62.40 & -18.53 & -7.21 & -.98 \\
\hline
\end{tabular}

\section{Estimation Results}

The results consist of three parts. First we use pooled regression models to analyze the importance of quality corrections and the effects of changes in exchange rates. The pooled regressions are based on the assumption of consumer preferences, i.e. elasticities being constant over time. In the second section we will estimate yearly regressions that reduce the time during which we assume constant parameters. In the third section we will use different matching rules to calculate price indices that will be compared to an official price index and to our hedonic results.

\subsection{Pooled Regression}

The approach with a double-logarithmic specification on a set of pooled cross-sections, that has been described as model (1) in section 2.3, is used to construct a price index. Model (2) is provided 
as a baseline for comparisons, it only includes time dummy variables. Model (3) and (4) use the same specifications on the RHS as models (1) and (2), however the dependent variable is expressed in terms of US Dollar values ${ }^{21}$. The large majority of components is not produced in Germany, but imported from Asia or from the US. Since the import price is paid in US Dollar and since the Dollar to Mark exchange rate has changed largely we use model (3) and (4) to check on possible impacts of exchange rates.

The time dummy variables in model (2) reflect the decline of average prices in our sample. The results show that by 1994, average prices had declined by about 62 percent from their initial 1985 levels. While we can compute a price index on the basis of these dummies (Models (2) and (4)), that index would be subject to the criticism that quality improvements are not taken into account. They will therefore merely serve as a baseline result against which our hedonic estimates in columns (1) and (3) can be compared.

Table 2 reports the coefficients for the hedonic quality variables in model (1) and model (3). The results of the time dummy variables for the models (1) to (4) are reported in Table 3. While the Coefficients for the time dummy variables show remarkable differences between the DM and the USD specification due to substantial changes in the exchange rates, the coefficients for the quality variables do not show significant differences. Given the non-linearity of the transformation that is applied to the dependent variable, the observation that only the time dummy variables are affected supports our basic assumption that the price development can be decomposed into a time and a quality component.

Ex ante theoretical considerations would let us expect that greater values of quality attributes are associated with higher prices for PC products and missing attributes, e.g. NOHD with lower prices. Therefore we expect positive coefficients for the estimated parameters for the characteristics.

${ }^{21}$ The exchange rates that were current at the time the advertisment was made are used. The data on exchange rates were provided by Datastream. 
Table 2: Hedonic Regression Results ${ }^{22}$

(Standard errors in parentheses)

\begin{tabular}{|c|c|c|c|c|c|}
\hline & & $\begin{array}{l}\log \text { (Pric } \\
{[\mathrm{DM}]}\end{array}$ & & $\begin{array}{l}\log (\mathrm{Pr} \\
\text { [US Do }\end{array}$ & \\
\hline & & Model (1 & & model & \\
\hline SPEED & LNICOMP & $0.300 *$ & $(0.007)$ & $0.301 *$ & $(0.007)$ \\
\hline & PROC32 & $0.250 *$ & $(0.008)$ & $0.253^{*}$ & $(0.008)$ \\
\hline & LNCACHE & 0.008 & $(0.007)$ & 0.009 & $(0.007)$ \\
\hline & NOCACHE & -0.011 & $(0.011)$ & -0.007 & $(0.011)$ \\
\hline & D_BUS16 & 0.007 & $(0.012)$ & 0.008 & $(0.012)$ \\
\hline & D_BUS32 & $0.194 *$ & $(0.016)$ & $0.190 *$ & $(0.016)$ \\
\hline CAPACITY & LNMEM & $0.147 *$ & $(0.007)$ & $0.144^{*}$ & $(0.007)$ \\
\hline & LNHDMB & $0.122 *$ & $(0.005)$ & $0.123^{*}$ & $(0.005)$ \\
\hline & NOHD & $-0.247 *$ & $(0.009)$ & $-0.246^{*}$ & (0.009) \\
\hline & D_FD2 & $0.039 *$ & $(0.007)$ & $0.040 *$ & $(0.007)$ \\
\hline & CD̄ROM & $0.055^{*}$ & $(0.011)$ & $0.057^{*}$ & $(0.011)$ \\
\hline VIDEO & LNDSIZE & $0.867^{*}$ & $(0.037)$ & $0.900 *$ & $(0.037)$ \\
\hline & D_DCOLOR & $0.173 *$ & $(0.006)$ & $0.173 *$ & $(0.006)$ \\
\hline & LNVMEM & $0.020 *$ & $(0.004)$ & $0.021^{*}$ & $(0.004)$ \\
\hline ACCESORIES & MOUSE & $0.025^{*}$ & $(0.009)$ & $0.022 *$ & $(0.009)$ \\
\hline & LNAPPS & $0.080^{*}$ & $(0.009)$ & $0.082 *$ & $(0.009)$ \\
\hline & NOAPPS & $-0.026^{*}$ & $(0.009)$ & $-0.028 *$ & $(0.009)$ \\
\hline & OS & $0.053 *$ & $(0.007)$ & $0.057^{*}$ & $(0.007)$ \\
\hline & TOWER & $0.025^{*}$ & $(0.006)$ & $0.026^{*}$ & $(0.006)$ \\
\hline & CONSTANT & 5.743 & $(0.111)$ & 4.534 & $(0.112)$ \\
\hline & $\mathrm{F}(58,10835)$ & 840.220 & & 739.68 & \\
\hline & Prob. $>$ F & 0.000 & & 0.000 & \\
\hline & $\mathrm{R}^{2}$ & 0.797 & & 0.774 & \\
\hline & Root MSE & 0.224 & & 0.225 & \\
\hline
\end{tabular}

* significant on $1 \%$ error level

These expectations are broadly confirmed in the estimates. Speed seems to be very important for the consumers. The performance index LNICOMP describes the computing power of the system. The effect of processor performance 0.300 (0.007) clearly dominates the effects of the other variables related to performance. Caching access to the main memory is only important for the faster 80386 processors or later generations, the effects of cache size come with the right signs, however they are not significant. The F-test $\mathrm{F}(2,10835)=3.01$ rejects the hypothesis that the coefficients of both variables LNCACHE and NOCACHE equal zero.

The introduction of the 32-Bit architecture was a major step in the development of personal computing. The dummy variable PROC32 shows the influence of the processor type on the price

\footnotetext{
${ }^{22}$ Note: The dependent variable is LNPRICE, the logarithm of the package's advertised price. Reference period is the first quarter in the year 1985. The time dummy variables are reported in Table 3. Heteroskedasticity-robust standard errors were computed using White's (1980) variance-covariance estimator.
} 
and thus its importance as a means of vertical differentiation. Since 1987 computers with the Intel 80386 processor were offered that gave way to graphical user interfaces and powerful database and spreadsheet applications. The strong effect of 32-Bit processing is shown by an elasticity of .25 which is highly significant (S.E. .008). This results are compatible with the findings of Bresnahan et al. (1996), reporting that 386 processors, which were frontier technology then, had a significant mark-up and helped to create separated market segments. In the years following 1990 more powerful processors required also faster access to peripheral devices and several 32-Bit bus architectures were introduced before Intel's PCI specification became the dominant standard. D_BUS32 had a strong positive impact compared to the weak effects of the 16-Bit ISA architecture that replaced the 8-Bit expansion system used by the original PC.

Greater capacity (higher values of LNHDMB and LNMEM) are also associated with significantly higher prices for database products, the respective elasticities being about 0.147 and 0.122 (standard errors 0.007 and 0.005). A second floppy disk drive and a CD-ROM drive are also positively correlated with the price of the package. As expected systems that do not come with a hard disk drive (NOHD) are sold with a significant discount (coeff. -.162).

The quality of the video system apparently seems to be of crucial importance to the user. The coefficient of LNDSIZE which represents the size of the display is at .867 (0.037). Presumably this variable does not only refer to the actual size of the display but also to other features like digital control, low radiation or higher refresh rates that are highly correlated to screen size and also represent some kind of quality improvements that are not explicitly modeled here. Furthermore packages including color displays were significantly more expensive than packages equipped with monochrome displays.

All variables describing accessories (MOUSE, TOWER, LNAPPS and OS) are positively correlated with the package's price, although they are not as important as the ones discussed before. These coefficients follow our expectations since improvements in quality should be associated with higher prices.

One should note that the price decline measured by the time dummy variables in model (1) is stronger than in the second regression, i.e. one would underestimate the price decline if one were willing to rely simply on an analysis of average prices without taking quality changes into account. In our estimates in model (1), the overall decline is 99 percent in the years 1985 to 1994, 37 percentage points higher than in the case of the regression on average prices in column (2).

Diagram 1 shows the development of the time dummy coefficients of model (1) to (4). The narrow 
confidence intervals visualize the precision of the estimation concerning the time dummy variables that are used to calculate the price index. Apparently the hedonic time series is decreasing constantly and is virtually untouched by changes in supply as e.g. the introduction of the new 386 generation or the burning at Sumitomo chemical plant ${ }^{23}$ or demand, e.g. the introduction of Windows 3.0. Whereas average prices rise in the years 1989 and 1990 when users started to migrate to MS-Windows and asked for more powerful 32-Bit computing systems.

Diagram 1: Time Dummy Coefficients 1985-1994

model(1)-model(4) PC Hardware

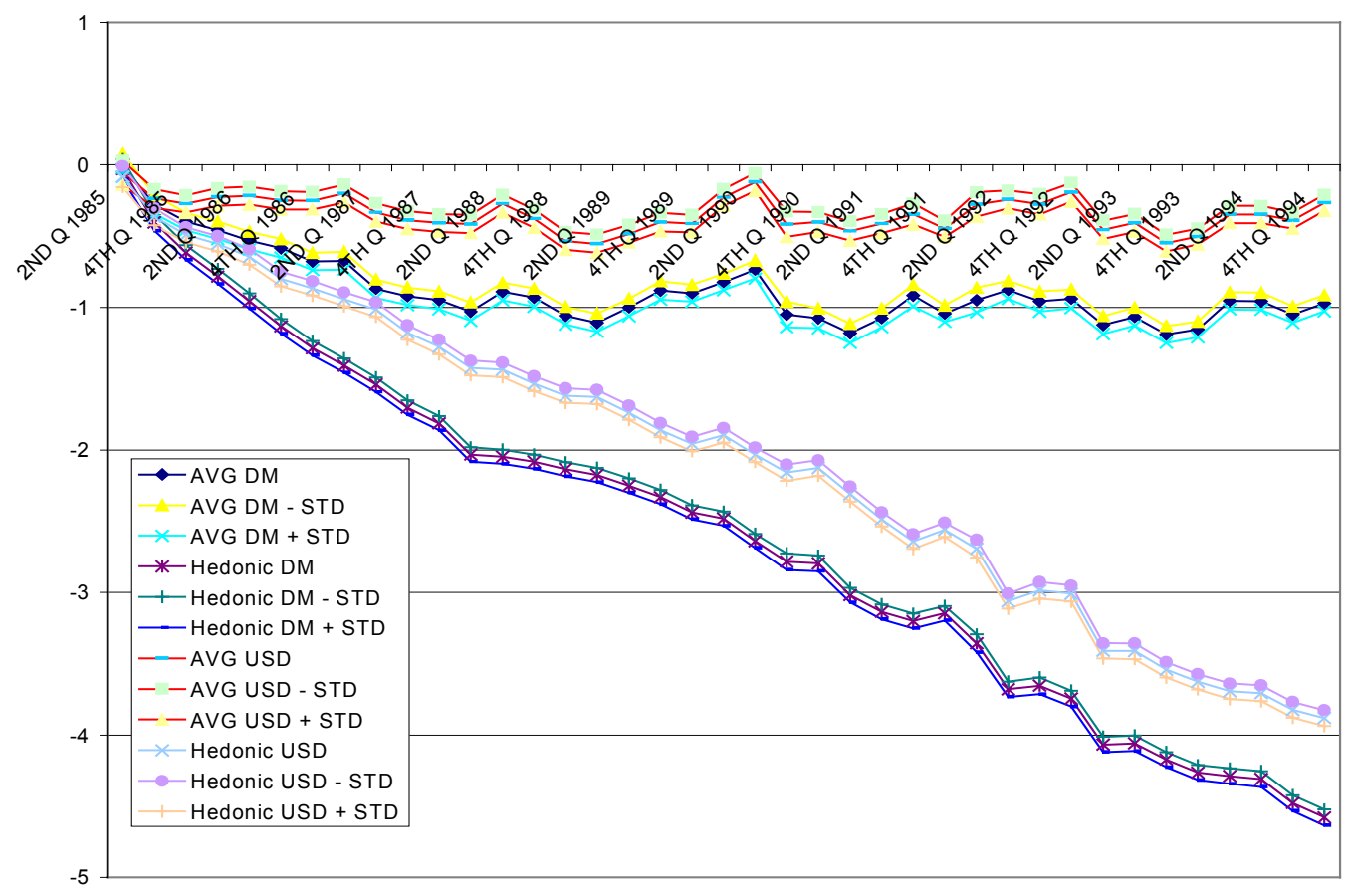

\subsection{Matched Model}

The construction of matched model indices was done using two matching rules. First only technically identical packages that had the same specification, the same producer, the same product name and were sold in the same outlet were considered to be identical (SHOP). In the second approach (ALL) the matching rule was less tight, it assumed that there were no quality differentials and considered all models equal. Because the matching on the shop level didn't even allow to

\footnotetext{
${ }^{23}$ Sumitomo was a monopolist producing about 90 percent of an epoxy glue that was used to fix the silicon chips. In 1990 there was a fire at the plant that destroyed the production facilities. Since it takes a high effort to produce this material at a high level of purity and because of the limited market size it is not profitable for other producers to enter the market. Thus the shortness in supply of epoxy led to a shortness in DRAM modules. In the aftermath of the burning prices rose sharply and remained at a high level for several months.
} 
construct an index on a quarterly level ${ }^{24}$, the matched model indices were calculated on a monthly basis.

\section{Diagram 2}

PC Price Indexes for Germany 1985-1994

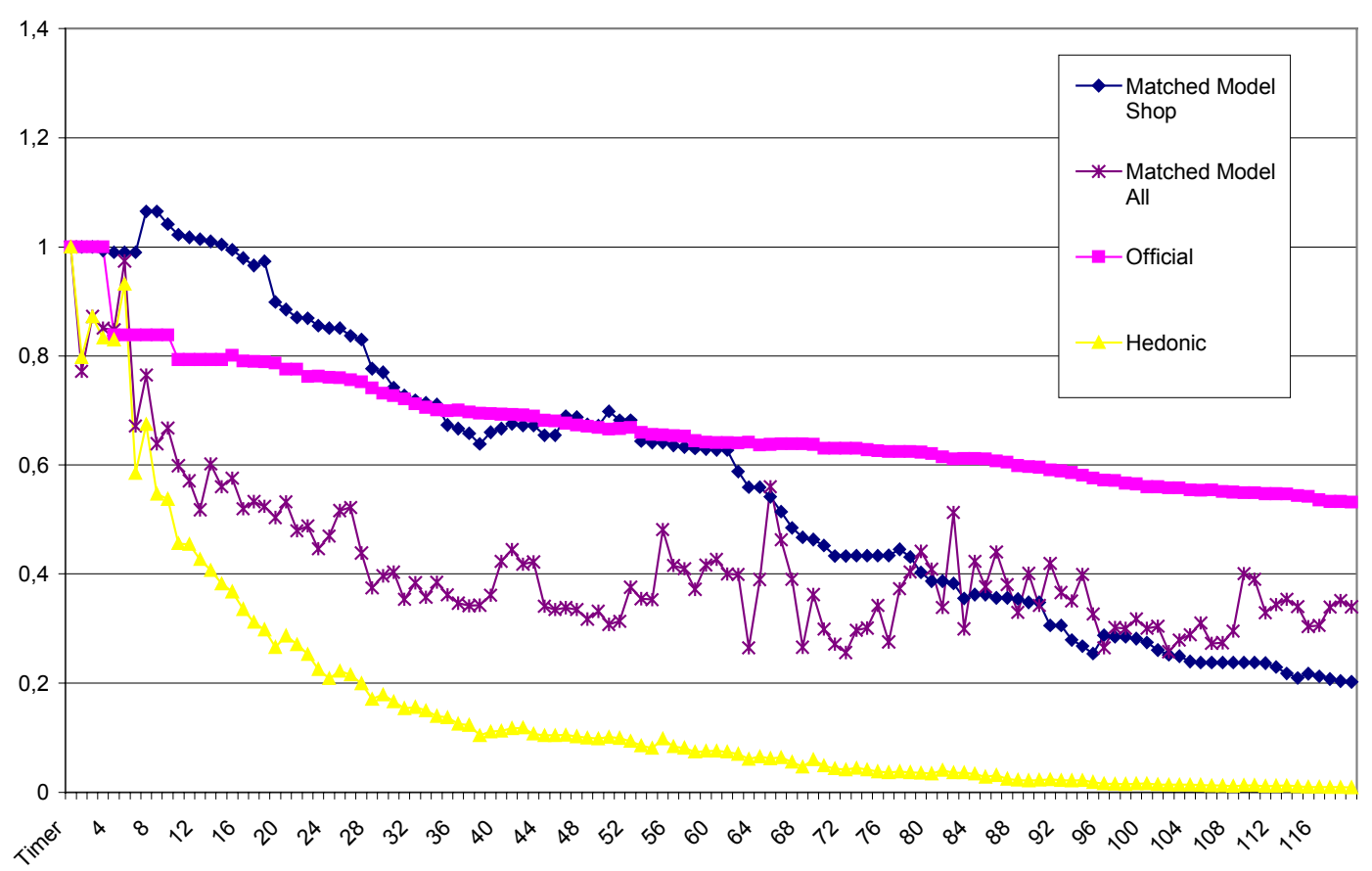

Diagram 2 shows the two matched model indices we obtained and compares them to a hedonic index according to our model (1) and to official data taken from the German consumer price index series $^{25}$.

Apparently, the rules used for matching matter. Matching on the level of identical products sold in the same outlet, gives us higher index numbers than using all observations. Due to the matching no special offers are considered, e.g. one outlet offering a brand product below the other outlet's price for one period and therefore advertising it only during that period. Furthermore small firms that are close to the market with low prices and frequent changes in product specifications will not be included. In any case the hedonic index declines faster than both the matched model index and the official index series.

\section{Conclusions and Summary}

Our results demonstrate the importance of quality changes for the price development in the PC

\footnotetext{
${ }^{24}$ We would have lost almost all observations, because typically product life cycles are shorter than a quarter if the tight identification rule is used.

${ }^{25}$ Statistical Office Germany, Wiesbaden Segment 3303, Reihe 505, Nr. 003270141
} 
market. The hedonic index for PC hardware declines on an average of about 34 percent p.a. during the years 1985-1994 showing the importance of quality improvements. Computer prices - nominal prices as well as quality adjusted prices- have been falling permanently at comparably high rates. Gordon (1990), Berndt and Griliches (1993), Nelson et al. (1994), and Berndt et al. (1995) have shown that in the U.S. quality-adjusted prices for PCs decline on average by 25-30 percent per annum. Our results show that quality-adjusted prices declined at 34 percent p.a. However, if we control for the impact of the exchange rate the prices in the German market decline at roughly 30 percent which is consistent with the results obtained for the U.S. This suggests that the computer market is driven by immense competition implying that computer manufacturers price their products at marginal cost.

The notion that prices heavily depend on exchange rates supports the assumption of a global market for PC hardware and visualizes the intense competition in that market. There are no signs that changes in the exchange rates, i.e. changes in the level of nominal prices, would create changes in elasticities, i.e. local changes in demand that would give room to arbitrage or market power.

The introduction of complementary software could have impacts on the demand for PC attributes. Their complementary effects could influence the valuation of a computer package consisting of hardware and software. The value of memory capacity for instance depends heavily on the resources needed by the operating system and the application software. If the utility of computer hardware and the hardware requirements of computer software used are highly interdependent and considering the change in hardware requirements from DOS to Windows applications we should expect considerable variations in attributes ${ }^{`}$ elasticities. However, in the specification used for the pooled regressions above, we assumed parameters to be constant over time. In future work we will have to test for this assumption by estimating yearly regressions. 


\section{References}

Berndt, E. R. and Z. Griliches (1993). Price Indexes for Microcomputers: An Exploratory Study, The University of Chicago Press.

Berndt, E. R., Z. Griliches and N. J. Rappaport (1995). "Econometric estimates of price indexes for personal computers in the 1990's." Journal of Econometrics(68): 243-268.

Boskin, M. J. (1997). “Lies, Damned Lies and (Faulty) Statistics.” International Economy(Jan./Feb.): 1418.

Boskin, M. J., E. R. Dullberger, R. J. Gordon, Z. Griliches and D. W. Jorgenson (1996). Report by the United States Advisory Board to Study the Consumer Price Index.

Bresnahan, T. F., S. Stern and M. Trajtenberg (1996). Market Segmentation and the Sources of Rents from Innovation : Personal Computers in the late 1980's. Cambridge, MA, USA, National Bureau of Economic Research, INC.: 32 .

Douwe, U. v. (1996). Die Technologiedynamik im Marktentwicklungsprozess : eine modellgestützte Analyse der Technologieevolution am Beispiel der Personal Computer. Bergisch Gladbach [u.a.], Eul.

EITO (1999). European Information Technology Observatory 1999.

Gnoss (1994). Neue Ansätze zur Berechnung von Preisindizes - Hedonic-Indizes in der amtlichen Statistik. Konferenzfolien in Wien.

Gordon, R. J. (1990). The Measurement of Durable Goods Prices. Chicago, The University of Chicago Press.

Griliches, Z. (1971). Price indexes and quality change : Studies in new methods of measurement. Cambridge/Mass., Harvard Univ. Pr.

Harhoff, D. and D. Moch (1997). "Price Indexes for PC Database Software and the Value of Code Compatibility." Research Policy 26: 509-520.

Hoffmann, J. (1998). Problems of Inflation Measurement in Germany. Frankfurt, Deutsche Bundesbank.

Muellbauer, J. (1974). "Household Production Theory, Quality and the "Hedonic Technique".” American Economic Review 64: 977-994.

Nelson, R. A., T. L. Tanguay and C. D. Patterson (1994). "A Quality-Adjusted Price Index for Personal Computers." American Statistical Association 12(1): 23-31.

Rosen, S. (1974). "Hedonic Prices and Implicit Markets: Product Differentiation in Pure Competition." Journal of Political Economy 82(January-February): 34 - 55.

Szenzenstein, J. (1995). Preisindizes für Güter in der amtlichen Statistik. Mannheim.

Trajtenberg, M. (1990). Economic Analysis of Product Innovation. London, Harvard University Press, Cambridge, Massachusetts.

Triplett, J. E. (1990). Hedonic Methods in Statistical Agency Environments: An Intellectual Biopsy. Chicago, The University of Chicago Press.

White, H. (1980). "A heteroskedasticity-consistent covariance matrix estimator and a direct test for heteroskedasticity." Econometrica 48: 817-830. 


\section{Data Appendix}

Table 3

Pooled Regression Models

(Standard Errors in parentheses)

\begin{tabular}{|c|c|c|c|c|}
\hline & \multicolumn{2}{|c|}{ Log (Price) [DM] } & \multicolumn{2}{|c|}{ Log (Preis) [US Dollar] } \\
\hline & Model (1) & Model (2) & Model (3) & Model (4) \\
\hline $2^{\mathrm{ND}} Q 1985$ & $-0.030(0.082)$ & $-0.003(0.082)$ & $-0.082(0.073)$ & $-0.055(0.084)$ \\
\hline $3^{\mathrm{RD}} \mathrm{Q} 1985$ & $-0.404(0.066)$ & $-0.277(0.066)$ & $-0.363(0.059)$ & $-0.236(0.066)$ \\
\hline $4^{\mathrm{TH}} \mathrm{Q} 1985$ & $-0.615(0.060)$ & $-0.397(0.060)$ & $-0.491(0.052)$ & $-0.273(0.060)$ \\
\hline $1^{\mathrm{ST}} \mathbf{Q} 1986$ & $-0.783(0.062)$ & $-0.458(0.062)$ & $-0.553(0.053)$ & $-0.225(0.063)$ \\
\hline $2^{\mathrm{ND}} Q \mathbf{Q} 1986$ & $-0.955(0.062)$ & $-0.531(0.062)$ & $-0.645(0.054)$ & $-0.217(0.063)$ \\
\hline $3^{\mathrm{RD}} \mathrm{Q} 1986$ & $-1.133(0.065)$ & $-0.585(0.065)$ & $-0.801(0.052)$ & $-0.250(0.065)$ \\
\hline $4^{\mathrm{TH}} \mathrm{Q} 1986$ & $-1.286(0.061)$ & $-0.677(0.061)$ & $-0.865(0.051)$ & $-0.252(0.061)$ \\
\hline $1^{\text {ST }} Q 1987$ & $-1.408(0.062)$ & $-0.672(0.062)$ & $-0.942(0.050)$ & $-0.200(0.063)$ \\
\hline $2^{\mathrm{ND}}$ Q 1987 & $-1.542(0.065)$ & $-0.868(0.065)$ & $-1.014(0.052)$ & $-0.334(0.065)$ \\
\hline $3^{\mathrm{RD}} \mathrm{Q} 1987$ & $-1.703(0.062)$ & $-0.921(0.062)$ & $-1.177(0.051)$ & $-0.388(0.063)$ \\
\hline $4^{\mathrm{TH}} \mathrm{Q} 1987$ & $-1.813(0.062)$ & $-0.949(0.062)$ & $-1.278(0.051)$ & $-0.407(0.062)$ \\
\hline $1^{\mathrm{ST}} \mathbf{Q} 1988$ & $-2.032(0.064)$ & $-1.029(0.064)$ & $-1.425(0.052)$ & $-0.415(0.064)$ \\
\hline $2^{\mathrm{ND}} Q \mathbf{Q} 1988$ & $-2.048(0.062)$ & $-0.889(0.062)$ & $-1.438(0.051)$ & $-0.273(0.063)$ \\
\hline $3^{\mathrm{RD}} \mathrm{Q} 1988$ & $-2.083(0.064)$ & $-0.931(0.064)$ & $-1.536(0.052)$ & $-0.377(0.065)$ \\
\hline $4^{\mathrm{TH}} \mathrm{Q} 1988$ & $-2.136(0.062)$ & $-1.058(0.062)$ & $-1.619(0.051)$ & $-0.534(0.062)$ \\
\hline $1^{\text {ST }}$ Q 1989 & $-2.176(0.064)$ & $-1.107(0.064)$ & $-1.629(0.051)$ & $-0.553(0.064)$ \\
\hline $2^{\mathrm{ND}}$ Q 1989 & $-2.250(0.062)$ & $-1.000(0.062)$ & $-1.739(0.051)$ & $-0.483(0.062)$ \\
\hline $3^{\mathrm{RD}} \mathrm{Q} 1989$ & $-2.331(0.065)$ & $-0.881(0.065)$ & $-1.861(0.051)$ & $-0.402(0.065)$ \\
\hline $4^{\mathrm{TH}} \mathrm{Q} 1989$ & $-2.437(0.060)$ & $-0.900(0.060)$ & $-1.959(0.051)$ & $-0.412(0.061)$ \\
\hline $1^{\mathrm{ST}} \mathbf{Q} 1990$ & $-2.482(0.057)$ & $-0.821(0.057)$ & $-1.897(0.051)$ & $-0.228(0.058)$ \\
\hline $2^{\mathrm{ND}} Q 1990$ & $-2.638(0.063)$ & $-0.734(0.063)$ & $-2.034(0.051)$ & $-0.121(0.063)$ \\
\hline $3^{\mathrm{RD}} \mathrm{Q} 1990$ & $-2.784(0.090)$ & $-1.050(0.090)$ & $-2.159(0.057)$ & $-0.418(0.089)$ \\
\hline $4^{\mathrm{TH}} \mathrm{Q} 1990$ & $-2.796(0.070)$ & $-1.077(0.070)$ & $-2.127(0.054)$ & $-0.402(0.070)$ \\
\hline $1^{\mathrm{ST}} \mathrm{Q} 1991$ & $-3.020(0.068)$ & $-1.182(0.068)$ & $-2.310(0.052)$ & $-0.464(0.068)$ \\
\hline $2^{\mathrm{ND}} \mathrm{Q} 1991$ & $-3.136(0.066)$ & $-1.074(0.066)$ & $-2.487(0.051)$ & $-0.413(0.067)$ \\
\hline $3^{\mathrm{RD}} \mathrm{Q} 1991$ & $-3.201(0.075)$ & $-0.915(0.075)$ & $-2.642(0.052)$ & $-0.345(0.075)$ \\
\hline $4^{\mathrm{TH}} \mathrm{Q} 1991$ & $-3.146(0.057)$ & $-1.043(0.057)$ & $-2.560(0.051)$ & $-0.448(0.057)$ \\
\hline $1^{\mathrm{ST}} \mathrm{Q} 1992$ & $-3.357(0.086)$ & $-0.948(0.086)$ & $-2.693(0.063)$ & $-0.278(0.086)$ \\
\hline $2^{\mathrm{ND}}$ Q 1992 & $-3.679(0.063)$ & $-0.877(0.063)$ & $-3.061(0.054)$ & $-0.243(0.063)$ \\
\hline $3^{\mathrm{RD}}$ Q 1992 & $-3.655(0.071)$ & $-0.958(0.071)$ & $-2.986(0.058)$ & $-0.276(0.071)$ \\
\hline $4^{\mathrm{TH}} \mathrm{Q} 1992$ & $-3.745(0.065)$ & $-0.939(0.065)$ & $-3.009(0.057)$ & $-0.192(0.066)$ \\
\hline $1^{\mathrm{ST}} \mathrm{Q} 1993$ & $-4.066(0.063)$ & $-1.124(0.063)$ & $-3.410(0.054)$ & $-0.455(0.063)$ \\
\hline $2^{\mathrm{ND}}$ Q 1993 & $-4.058(0.063)$ & $-1.065(0.063)$ & $-3.412(0.055)$ & $-0.407(0.063)$ \\
\hline $3^{\mathrm{RD}} \mathrm{Q} 1993$ & $-4.172(0.059)$ & $-1.190(0.059)$ & $-3.543(0.054)$ & $-0.549(0.059)$ \\
\hline $4^{\mathrm{TH}} \mathrm{Q} 1993$ & $-4.264(0.056)$ & $-1.155(0.056)$ & $-3.626(0.054)$ & $-0.503(0.056)$ \\
\hline $1^{\text {ST }}$ Q 1994 & $-4.288(0.060)$ & $-0.953(0.060)$ & $-3.693(0.055)$ & $-0.348(0.060)$ \\
\hline $2^{\mathrm{ND}}$ Q 1994 & $-4.309(0.060)$ & $-0.957(0.060)$ & $-3.707(0.056)$ & $-0.348(0.060)$ \\
\hline $3^{\mathrm{RD}} \mathrm{Q} 1994$ & $-4.478(0.057)$ & $-1.050(0.057)$ & $-3.823(0.056)$ & $-0.390(0.057)$ \\
\hline $4^{\mathrm{TH}}$ Q 1994 & $-4.578(0.057)$ & $-0.971(0.057)$ & $-3.881(0.056)$ & $-0.266(0.057)$ \\
\hline CONSTANT & $5.743(0.055)$ & $9.135(0.055)$ & $4.534(0.112)$ & $8.000(0.055)$ \\
\hline $\mathbf{F}(39,10854)$ & & 81.970 & & 22.300 \\
\hline$F(58,10835)$ & 840.220 & & 739.68 & \\
\hline Prob $>$ F & 0,000 & 0.000 & 0.000 & 0.000 \\
\hline R-Sqrd & 0.797 & 0.155 & 0.774 & 0.057 \\
\hline Root MSE & 0.224 & 0.457 & 0.225 & 0.458 \\
\hline
\end{tabular}




\section{Table 4}

Annual Growth rates (percent) for Prices of PC Products 1982-1994

\begin{tabular}{|c|c|c|c|c|c|c|c|c|c|c|c|c|c|}
\hline Price Index & $\begin{array}{c}1982 \\
- \\
1983\end{array}$ & $\begin{array}{c}1983 \\
- \\
1984\end{array}$ & $\begin{array}{c}1984 \\
- \\
1985\end{array}$ & $\begin{array}{c}1985 \\
- \\
1986\end{array}$ & $\begin{array}{c}1986 \\
- \\
1987\end{array}$ & $\begin{array}{c}1987 \\
- \\
1988\end{array}$ & $\begin{array}{c}1988 \\
- \\
1989\end{array}$ & $\begin{array}{c}1989 \\
- \\
1990\end{array}$ & $\begin{array}{c}1990 \\
- \\
1991\end{array}$ & $\begin{array}{c}1991 \\
- \\
1992\end{array}$ & $\begin{array}{c}1992 \\
- \\
1993\end{array}$ & $\begin{array}{c}1993 \\
- \\
1994\end{array}$ & AAGR \\
\hline $\begin{array}{c}\text { Average Prices for PC Database Software } \\
\text { Harhoff and Moch (1997) }\end{array}$ & & & & & $-3 \%$ & $-14 \%$ & $+6 \%$ & $-6 \%$ & $-16 \%$ & $+1 \%$ & $0 \%$ & $-8 \%$ & $-5 \%$ \\
\hline $\begin{array}{c}\text { Hedonic Prices for PC Database Software } \\
\text { Harhoff and Moch (1997) }\end{array}$ & & & & & $-4 \%$ & $-15 \%$ & $+1 \%$ & $-6 \%$ & $-6 \%$ & $-4 \%$ & $-7 \%$ & $-14 \%$ & $-7 \%$ \\
\hline Average Prices for PC Hardware & & & & $-22 \%$ & $-24 \%$ & $-11 \%$ & $0 \%$ & $+13 \%$ & $-18 \%$ & $+13 \%$ & $-20 \%$ & $+17 \%$ & $-7 \%$ \\
\hline Hedonic Prices for PC Hardware & & & & $-41 \%$ & $-41 \%$ & $-35 \%$ & $-20 \%$ & $-22 \%$ & $-43 \%$ & $-36 \%$ & $-41 \%$ & $-21 \%$ & $-34 \%$ \\
\hline Matched Model Index Shop & & & & $-7 \%$ & $-19 \%$ & $-13 \%$ & $-2 \%$ & $-20 \%$ & $-21 \%$ & $-21 \%$ & $-20 \%$ & $-15 \%$ & \\
\hline Matched Model Index All & & & & $-31 \%$ & $-21 \%$ & $-10 \%$ & $0 \%$ & $+1 \%$ & $-5 \%$ & $+7 \%$ & $-23 \%$ & $+18 \%$ & \\
\hline $\begin{array}{l}\text { Official Index for Germany } \\
\text { Statistical Office }\end{array}$ & & & & $-11 \%$ & $-7 \%$ & $-6 \%$ & $-4 \%$ & $-3 \%$ & $-2 \%$ & $-4 \%$ & $-6 \%$ & $-3 \%$ & \\
\hline $\begin{array}{c}\text { Hedonic Prices for PC Hardware } \\
\text { US Market } \\
\text { Berndt et al. (1995) }\end{array}$ & $-33 \%$ & $-1 \%$ & $-36 \%$ & $-34 \%$ & $-28 \%$ & $-35 \%$ & & $-26 \%$ & $-10 \%$ & $-\% 52$ & & & $-30 \%$ \\
\hline $\begin{array}{l}\text { Hedonic Prices for Hardware } \\
\text { Major Brands, US Market } \\
\text { Nelson et al. (1994) }\end{array}$ & & & $+2 \%$ & $-28 \%$ & $-26 \%$ & $+1 \%$ & $-9 \%$ & $-26 \%$ & $-13 \%$ & & & & $-15 \%$ \\
\hline $\begin{array}{l}\text { Hedonic Prices for Hardware } \\
\text { Mail Order, US Market } \\
\text { Nelson et al. (1994) }\end{array}$ & & & $+3 \%$ & $-59 \%$ & $-13 \%$ & $-8 \%$ & $-5 \%$ & $-34 \%$ & $-27 \%$ & & & & $-23 \%$ \\
\hline
\end{tabular}

